\title{
Peripherally-inserted Central Catheter (PICC) Insertion in Neonates: Apnea and Radiocontrasts Complications
}

Eissa Bilehjani ${ }^{1}$, Solmaz Fakhari ${ }^{* 1}$, Touraj Asvadi Kermani ${ }^{2}$

1. Department of Anesthesiology, Tabriz University of Medical Sciences, Tabriz, Iran

2. Department of Surgery, Tabriz University of Medical Sciences, Tabriz, Iran

The importance of pain management throughout minimally-invasive procedures such as peripherally-inserted central catheter (PICC) insertion is an inevitable fact. However, administration of varied analgesics, especially opioids, in specific age ranges such as neonate could be of immense concern. Most of these patients are on different medications, especially those hospitalized in the ICUs or with critical conditions. Neonates receiving continuous opioid infusions might also require an additional opioid bolus to control the associated pain (1). Importantly, it should be taken into consideration that administration of opioids or even a light sedation would increase the risk of delayed apnea in this group of patients (2). Factors contributing to this complication include ex-premature infants (gestational age $<37$ weeks), premature infants younger than 46 weeks' postconceptual age and anemia (hematocrit< $30 \%)(3,4)$. Hence, it is recommended to use other supplementary analgesic techniques including local or topical anesthesia, especially in neonates having previously received continuous or bolus opioids. Furthermore, supplementary techniques assisting the confirmation of proper placement such as overpenetrating the radiograph, lateral $\mathrm{X}$-rays and positioning the infant for a lateral oblique radiograph (right side elevated at a $10^{\circ}-15^{\circ}$ angle) are frequently used by clinicians to avoid administration of radiocontrasts and their associated complications. In the latter technique, catheter visualization could be enhanced as the PICC will not be superimposed over the mediastinal structures $(5,6)$.

\section{Corresponding author:}

Solmaz Fakhari, MD

Department of Anesthesiology, Tabriz University of Medical Sciences, Golgasht St., Tabriz, Iran

E-mail: solmaz_fakhari@yahoo.com; fakharis@tbzmed.ac.ir Phone: +989144024929

Receive date: 2014-11-01| Accept date: 2014-11-14| Publish date: 2014-12-01

DOI: 10.7575/aiac.abcmed.15.03.01.11

\section{A. I}




\section{References}

1. McCay As, Elliott EC, Walden M. PICC Placement in the Neonate. N Engl J Med 2014; 370:e17. DOI: 10.1056/NEJMvcm1101914

2. William JM, Stoddart PA, Williams SA, Wolf AR: Post-operative recovery after inguinal herniotomy in ex-premature infants: Comparison between sevoflurane and spinal anaesthesia. Br J Anaesth 2001; 86:366-371.

3. Fisher DM: When is the ex-premature infant no longer at risk for apnea?. Anesthesiology 1995; 82:807.

4. Welborn LG, Hannallah RS, Luban NL, et al: Anemia and postoperative apnea in former preterm infants. Anesthesiology 1991; 74:1003.

5. Petit J, Wyckoff MM. Peripherally inserted central catheters. Guideline for practice, second edition. 2007. 